\title{
REVISTA PEDAGÓGICA
}




\begin{tabular}{cc}
\hline 37(05) & $\begin{array}{c}\text { Revista Pedagógica, -- Chapecó : } \\
\text { R454r }\end{array}$ \\
& Argos, 2009. \\
n. 22, ano 11. \\
1. Educação - Periódicos - 2. \\
Pedagogia - Periódicos. I. Título
\end{tabular}

ISSN 1984-1586 (www.unochapeco.edu.br/revistas/pedagogica)

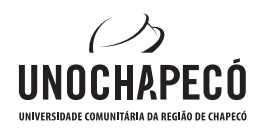

Av. Senador Atílio Fontana, 591-E, Fone (49) 3321 8000, Cx. Postal 1141, Cep: 89809-000 - Chapecó (SC)

Reitor: Odilon Luiz Poli

Vice-Reitora de Ensino, Pesquisa e Extensão: Maria Luiza de Souza Lajus Vice-Reitor de Planejamento e Desenvolvimento: Claudio Alcides Jacoski Vice-Reitor de Administração: Sady Mazzioni

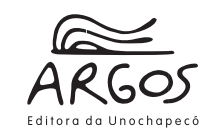

Coordenador: Valdir Prigol

Assistente Editorial: Alexsandro Stumpf

Diagramação: Caroline Kirschner

Capa: Ronise Biezus

A partir da obra "Visual Music", 1922, de Paul Klee

A revisão dos textos é de responsabilidade dos autores dos artigos.

\title{
REVISTA PEDAGÓGICA
}

Centro de Ciências da Educação

Diretor de Centro: Vilmar Araújo de Souza

Coordenação Editorial: Maria dos Anjos Lopes Viella

\section{Conselho Editorial Externo}

Alda Junqueira (UNESP - Araraquara/PUC/SP); Alice Áurea Penteado Martha (UEM - Maringá); Alessandra Santana Soares de Barros (UFBA); Angela Vorcaro (UFMG); Armindo Quilicci Neto (UFU - MG); Arnaldo Franco Júnior (UEM - Maringá); Célia Regina Vendramini (UFSC); Cristiano Mauro Assis Gomes (UFMG); Dóris Anita Freire Costa (CEPEMG - UEMG); Elsie Masini (Uni. Makenzie); Ernesto Giovanni Boccara (UNICAMP); Eurize Caldas Pessanha (UFMS); Fabiany de Cássia Tavares Silva (UFMS); Giana Lange do Amaral (UFPel); Ida Mara Freire (UFSC); Inês Lacerda Araújo (PUCPR); Isabel Brasil Pereira (ibrasil@fiocruz.br); Isilda Campaner Palangana (UEM); José Manoel Moran (USP); Léa das Graças C. Anastasiou (PUCPR); Luciana Karine de Souza (UFMG); Magda B. Soares (UFMG); Maria Eugênia L. M. Castanho (PUC - Campinas); Maria Helena S. Bonilla (UFBA); Maria Inês Bacellar Monteiro (UNIMEP); Maria Isabel da Cunha (UNISINOS); Marlene Ribeiro (UFRGS); Maurício Roberto da Sillva (UFSC); Neli de Freitas Klix (UDESC); Nelson Antônio Pirola (UNESP - Bauru); Neusa M. Mendes Gusmão (Unicamp); Rafael Cordeiro Silva (UFU); Renilson José Menegassi (UEM); Regina Mutti (UFRGS); Rosa M. Graciotto Silva (UEM - Maringá); Sandra Regina Ramalho (UDESC); Sueli Soares dos Santos Batista (SEE - Itatiba - SP)

\author{
Parecerista Internacional \\ Helena Damião (Universidade de Coimbra - Portugal) \\ Beatriz Perez González (Universidade Cádiz - Espanha) \\ Comissão Editorial Interna \\ Ireno Antonio Berticelli; Ione Inês Pinsson Slongo; Ricardo Rezer; Valdir Prigol \\ Indexada pelo MEC/CIBEC \\ Bibliografia Brasileira de Educação (BBE) \\ IRESIE (Indice de Revistas de Educación Superior e Investigación Educativa) CESU / UNAM México.
}




\title{
SUMÁRIO
}

\author{
Editorial
}

5

Teoria fenomenográfica e concepções de aprendizagem

Luiz Gustavo Lima Freire

9

O envolvimento parental nas instituições de educação infantil

Sara Lúcia G. Ferreira

Márcia Andréia Triches

39

Reduciendo la familia, extendiendo las redes

Beatriz Pérez González

Julio Pérez González

57

Tecnologia e implicações na educação

Odete Catarina Locatelli

71

A experiência docente na prática de ensino/estágio curricular supervisionado em educação física dos acadêmicos do

CEFD/UFSM (currículo 1990)

Franciele Roos da Silva Ilha

Rodrigo de Rosso Krug

Hugo Norberto Krug

85

Fotografias de prédios escolares: a construção de obras visíveis como propaganda do governo Simões Lopes,

na cidade de Pelotas.

Maria Augusta Martiarena de Oliveira

Elomar Antonio Callegaro Tambara

Giana Lange do Amaral

109 
Pedagogias dos corpos excitáveis e moduláveis: sexo, amor e insatisfações aos vinte cinco anos da revista Nova Cosmopolitan

Dolores Galindo

133

\author{
Entrevista \\ Mercantilização da educação superior \\ e o fazer docente \\ Gaudêncio Frigotto
}

155 


\section{EDITORIAL}

Registramos nossa alegria pela acolhida que a Revista Pedagógica vem recebendo de pesquisadores de Portugal e Espanha, assim como de pesquisadores brasileiros de diferentes Estados que têm nos enviado suas colaborações. Agradecemos a todos pela confiança que têm depositado nesse periódico enquanto instrumento de divulgação do resultado de diferentes pesquisas que vem sendo realizadas na direção de imprimir maior clareza nas questões que tem se colocado para o quotidiano educacional.

Abrimos esse número com a contribuição de Luiz Gustavo Lima Freire em relação à Teoria fenomenográfica e concepções de aprendizagem. $\mathrm{O}$ autor inicia suas reflexões afirmando que as concepções de aprendizagem refletem e simultaneamente condicionam, tanto o próprio fenômeno da aprendizagem, quanto a forma dos estudantes se comportarem em relação a ele. Nessa direção vai defender a idéia de que o mapeamento conceitual desse fenômeno é prioritário para a compreensão dos insucessos acadêmicos e também para a promoção de mudanças das próprias concepções podendo culminar com a conquista de aprendizagens mais ricas. Assim, situa o leitor em relação às bases nas quais se ancoram a teoria fenomenográfica, os caminhos percorridos para realizar o mapeamento dessas concepções de aprendizagem dos estudantes, entre outros aspectos, e afirma que a principal tarefa dessa perspectiva é descrever as várias representações da aprendizagem, de modo a refletir sobre esse fenômeno e poder interferir na qualidade do que se aprende. $\mathrm{Na}$ medida em que os professores conheçam as concepções dos seus estudantes, poderão direcionar suas aulas e incentivar o uso de estratégias de aprendizagem mais construtivas e ou adaptadas.

Além de situar com o devido rigor teórico-metodológico essa forma de conceber o fenômeno da aprendizagem, ora como aquisição mecânica de conhecimentos (concepção quantitativa) e ora como compreensão do conhecimento (concepção qualitativa), complementa tais análises apresentando a existência de outras concepções que se posicionam entre as concepções quantitativa e qualitativa e ainda 
contribui com a apresentação das taxonomias descritivas para organizar as diversas representações acerca da aprendizagem. O artigo coloca em pauta uma perspectiva pouco debatida na atualidade mas que vai ganhando corpo suscitando a continuidade de mais investigações nessa área para melhoria das práticas de ensino-aprendizagem.

Sara Ferreira e Márcia Andréia, ambas de Portugal (Universidade do Aveiro e Universidade do Porto respectivamente) colaboram nesse número refletindo sobre a relação entre a família e a instituição de educação infantil focando vantagens e constrangimentos, modalidades de trabalho, competências educativas e estratégias de envolvimento, entre outros aspectos. $\mathrm{O}$ artigo em pauta traz contribuições para ampliar a discussão sobre a relevância da participação parental na escola, apresentando perspectivas de diferentes autores que apontam as possibilidades e limites dessa participação. Mencionam estudos que desmentem que todas as práticas de envolvimento parental nas instituições produziram impactos positivos no desempenho das crianças e inclusive "revelam alguma promiscuidade dos pais provenientes das classes média e alta na maioria das associações de pais, por utilizarem, pontualmente, $\mathrm{o}$ seu poder de participação na tomada de decisões a favor dos seus próprios filhos, dificultando, dessa forma, alterações na estrutura e nas práticas das instituições e preservando - ou até acentuando-mais as desigualdades culturais existentes".

$\mathrm{O}$ artigo seguinte, de Beatriz Pérez González e Julio Pérez González, discute também sobre a temática da familia na perspectiva da comunicação e dos vínculos que se estabelecem entre seus membros na sociedade urbana. Em decorrência das mudanças sócio-tecnológicas esses vínculos se estendem descrevendo outras tendências nas relações intrafamiliares, isto é "una extensión de redes artificiales como prolongándose en un espacio tecnológico frente a la real reducción de lazos interfamilias". No decorrer do texto os autores vão apontando fatores que contribuem para esse redimensionamento da família, pontuando aquilo que denominam de "utilidade e economia das relações" e a ligação de tudo isso com as políticas sociais e familiares em alguns países da Europa.

Odete Locatelli focaliza em seu artigo as possibilidades que se abrem para a educação com o advento das tecnologias da informação e comunicação assim como as exigências colocadas na formação de 
professores para lidarem com elas. Ao mesmo tempo em que exigências são postas para sua utilização há um contraponto dos benefícios propiciados por ela na prática dos educadores.

A História da experiência docente na prática de ensino/estágio curricular supervisionado em educação física, dos acadêmicos do CEFD/UFSM, artigo de Franciele Roos da Silva Ilha, Rodrigo de Rosso Krug e Hugo Norberto Krug, apresenta elementos para pensar as práticas pedagógicas nas escolas a partir de evidências empíricas realçadas pelos autores na pesquisa de campo. Essa experiência docente, de acadêmicos, na forma de estágio supervisionado está repleta de expectativas e acaba por revelar aquilo que, na representação dos alunos/docentes, constitui os melhores e os piores momentos dessa vivência, constituindo um retrato vivo da prática docente em que o professor-aluno tem muito a dizer e a ensinar.

$\mathrm{O}$ artigo Fotografias de prédios escolares: a construção de obras visíveis como propaganda do governo Simões Lopes, na cidade de Pelotas, de Maria Augusta Martiarena de Oliveira, Elomar Antonio Callegaro Tambara e Giana Lange do Amaral mostra como um grande grupo de imagens que tinham como tema a educação foi produzido durante o governo de Augusto Simões Lopes, intendente da cidade de Pelotas, pelo Partido Republicano Rio-Grandense, entre 1924 e 1928. Utilizando-se de fotografias publicadas no jornal Diário Popular órgão oficial do Partido Republicano Rio-Grandense e no Almanach de Pelotas, os autores afirmam que nenhum intendente anterior produziu um conjunto tão significativo de imagens relacionadas a esse tema, sendo essa uma característica bastante inovadora entre os governantes municipais e que revela também, através da propaganda, o desejo de continuidade de uma carreira política e que o lugar que a fotografia ocupa nesse contexto, não é inocente.

Pedagogias dos corpos excitáveis e moduláveis: sexo, amor e insatisfações aos vinte cinco anos da revista Nova Cosmopolitan, de Dolores Galindo inscreve-se nos estudos sobre gênero a partir da análise sobre a temática sexual e amorosa numa revista da atualidade a Nova Cosmopolitan. Ao ressaltar os sentidos sobre sexo e amor representados na revista deixa evidente que o sexo se inscreve na busca pela intensificação das sensações, avizinhando-se do consumo 
de exercícios que faz da academia de ginástica um dos espaços centrais na contemporaneidade. Essa "pedagogia dos corpos" vai permeando todo o desenvolvimento da análise realizada pela autora, apontando a exacerbação das sensações substituindo o controle e ocultação dos corpos que, historicamente, caracterizou a apresentação do sexo na imprensa feminina.

Por último apresentamos uma entrevista feita com o Professor Gaudêncio Frigotto discutindo Mercantilização da educação superior e o fazer docente, no intervalo de um momento de trabalho com os professores da Unochapecó. 